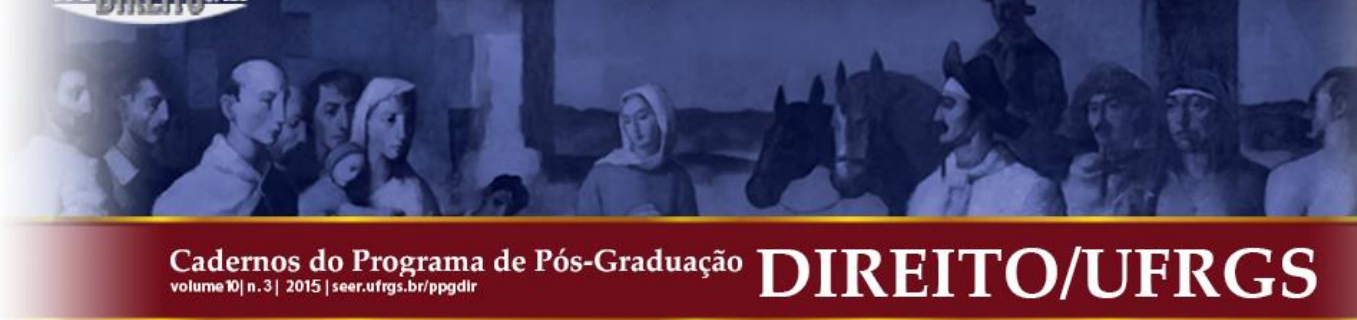

\title{
ASPECTOS POLÊMICOS DA MEDIAÇÃO JUDICIAL BRASILEIRA: UMA \\ ANÁLISE À LUZ DO NOVO CÓDIGO DE PROCESSO CIVIL E DA LEI DA MEDIAÇÃO
}

\author{
CONTROVERSIAL ASPECTS OF JUDICIAL MEDIATION IN BRASIL: AN ANALYSIS IN \\ THE LIGHT OF THE NEW BRAZILIAN CODE OF CIVIL PROCEDURE AND OF THE \\ MEDIATION LAW
}

\section{Karime Silva Siviero*}

\begin{abstract}
RESUMO: Os debates mais recentes sobre a ineficiência do Judiciário lançaram luz sobre a importância dos meios alternativos de tratamento dos conflitos na administração da Justiça. Com o objetivo de recobrar o passo rumo aos ideais modernos de pacificação social, o legislador brasileiro finalmente normatizou a mediação no novo Código de Processo Civil e na recém-sancionada Lei de Mediação (Lei n. ${ }^{\circ}$ 13.140/2015). Nessa linha, o presente artigo objetiva abordar as inovações trazidas pelos marcos legais da mediação à luz das exigências intrínsecas do instituto analisado. Tenciona-se demonstrar que a mediação judicial poderá se converter em importante ferramenta de educação dos jurisdicionados para a autonomia cidadã, além de servir de baliza de contenção para o arbítrio dos magistrados na condução dos processos. Não se pretende, obviamente, esgotar a análise de todas as questões relacionadas à institucionalização da mediação, mas apenas lançar luz sobre pontos importantes relacionados ao tema.
\end{abstract}

PALAVRAS-ChAVE: Mediação de conflitos. Novo Código de Processo Civil. Lei de Mediação. Acesso à justiça.
ABSTRACT: The latest debates on the inefficiency of the judiciary shed light on the importance of the alternative methods of conflict resolution in the administration of justice. In order to recover step towards the modern ideals of social pacification, the Brazilian legislature finally regulated the judicial mediation in the new Brazilian Code of Civil Procedure, as well as in the recently sanctioned Mediation Law (Law no. 13140 / 2015). Therefore, this paper aims to analyze the innovations brought by the legal framework in the light of requirements intrinsic to the analyzed institute. It is intended to demonstrate that judicial mediation may become an important educational tool of the subjected to jurisdiction for citizen autonomy, besides serving as a barrier to the arbitrariness of judges in the conduct of proceedings. It is not intended, obviously, to exhaust the analysis of all issues related to the institutionalization of mediation, but only to shed light on important points related to the theme.

KEYWORDS: Judicial mediation. New Brazilian Code of Civil Procedure. Mediation Law. Access to Justice.

SUMÁRIO: Introdução. 1. A mediação de conflitos no Novo Código de Processo Civil. 1.1. A obrigatoriedade da mediação. 1.2. A presença dos juízes na sessão de mediação. 1.3. A cumulação das funções de mediador e advogado. 1.4. A imparcialidade do mediador. 1.5. As sessões virtuais de mediação. 2. A Lei de Mediação (Lei n. ${ }^{\circ}$ 13.140/2015). Conclusão. Referências.

\section{INTRODUÇÃO}

A primeira proposta de regulamentação da mediação no Brasil surgiu com o Projeto de Lei n. ${ }^{\circ} 4.827 / 1998$, apresentado à Câmara pela Deputada Federal Zulaiê Cobra e que tinha a intenção de institucionalizá-la como método de prevenção e solução consensual de conflitos.

Referido Projeto de Lei foi aprovado pela Comissão de Constituição e Justiça da Câmara e remetido ao Senado, onde recebeu o número PLC n..$^{\circ}$ 94/2002. Em 2004, com o advento da Emenda Constitucional $n^{\circ} 45 / 2004$, o texto precisou ser adequado às novas

\footnotetext{
* Mestra em Direito pela Universidade Federal do Espírito Santo - UFES. Graduada em Direito pela mesma instituição. Coordenadora do Núcleo de Prática Jurídica da Universidade Vila Velha - UVV/ES. Tem experiência na área de Direito, com ênfase em Direito Civil, Direito Processual Civil e Direito do Trabalho.
} 


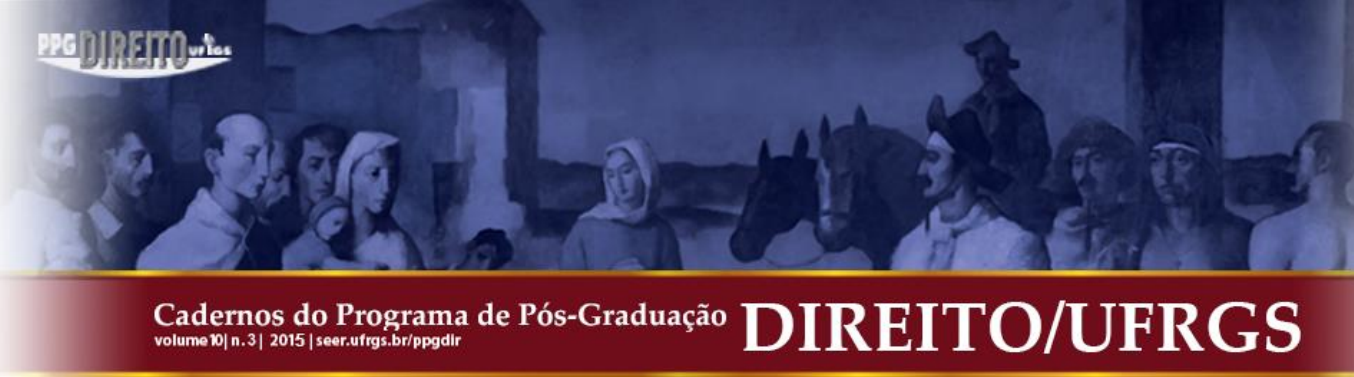

disposições constitucionais. Aprovou-se, então, a Emenda n 1 -CCJ, encaminhada à Câmara em julho de 2006, após o que nada mais se disse sobre a sua tramitação.

A última versão do Projeto propunha no artigo $1^{\circ}$ que a mediação paraprocessual civil poderia ser prévia, incidental, judicial ou extrajudicial. O requerimento para a mediação prévia judicial interromperia a prescrição e deveria ser finalizada em até noventa dias (artigo 29). Por outro lado, a mediação incidental seria, como regra, obrigatória para os processos de conhecimento, salvo para as exceções previstas em lei (artigo 34). Também neste último caso, o processo deveria ficar suspenso pelo período de 90 dias e, caso não houvesse possibilidade de acordo, o processo deveria ser retomado.

A simples distribuição da petição inicial ao juízo competente interromperia o prazo prescricional, induziria litispendência e produziria os mesmos efeitos previstos 263 e 219 do CPC. O projeto também ressalvava que o magistrado somente poderia suspender o processo e encaminhá-lo para a mediação após o exame dos pedidos de liminar, sendo que eventual interposição de recurso em face da decisão interlocutória provisional não afetaria o processo de mediação.

Apesar da boa técnica empregada - que apresentara uma regulamentação concisa e objetiva da mediação, apresentando o conceito do instituto e elencando algumas disposições a respeito -, o Projeto de Lei não foi à frente.

A mediação somente voltou à pauta legislativa em 2009, ano em que uma Comissão de Juristas presidida pelo Ministro Luiz Fux foi convocada para redigir um novo Código de Processo Civil (NCPC). O Anteprojeto, convertido no Projeto de Lei ${ }^{\circ}$ 166/10, tratava dos meios consensuais de pacificação na Seção V, intitulada "dos conciliadores e dos mediadores judiciais" (artigos 134 a 144).

O texto do Projeto foi aprovado pelo Pleno do Senado com apenas duas alterações e seguiu para a Câmara dos Deputados, onde foi autuado como PL n 8.046/2010. A nova versão do Senado alterou mais de 400 dispositivos do Anteprojeto.

Em 2011 as discussões sobre o texto do NCPC foram ampliadas. Por meio de atividades conjuntas desenvolvidas pela Comissão de Juristas, pela Câmara dos Deputados e pelo Ministério da Justiça, chamaram-se à participação nos debates a sociedade civil e a comunidade acadêmica. $\mathrm{O}$ texto tramitou por mais cinco comissões de análise dos anos seguintes, sendo a versão provisória com as alterações sugeridas pela Câmara liberada em junho de 2012.

Cadernos do Programa de Pós-Graduação em Direito PPGDir./UFRgS | Edição Digital | Porto Alegre | Volume X | Número 3 | 2015 | P. 316 -337 


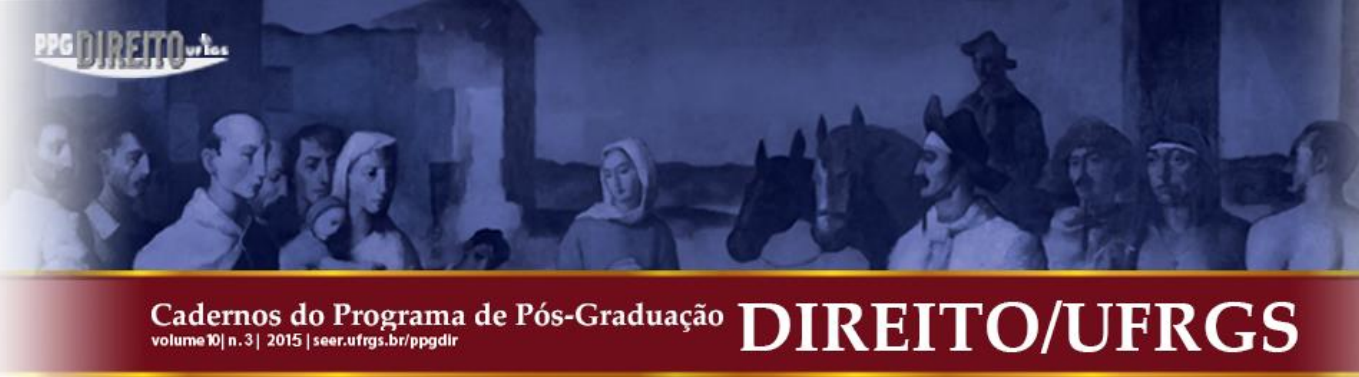

Após sofrer uma extensa revisão no Senado Federal, o texto foi encaminhado para a Presidência da República em fevereiro de 2015 e sancionado no mês seguinte.

Finalmente, um novo marco regulatório da mediação vem à lume em junho com a sanção da Lei de Mediação (lei n. ${ }^{\circ}$ 13.140/2015), que disciplina a mediação judicial e extrajudicial como forma de solução de conflitos.

O novo cenário normativo vem acompanhado de muitas inquietações: afinal, qual o prognóstico da mediação de conflitos no Judiciário brasileiro? Quais desafios serão enfrentados pelos mediadores e operadores do Direito em razão da aproximação entre justiça consensuada e justiça adjudicatória?

Estas são precisamente as indagações a que se pretende responder. Para tanto, far-se-á uma leitura sistemática do regramento jurídico dispensado a este mecanismo autocompositivo pelo Novo Código de Processo Civil e pela Lei de Mediação, levando-se em consideração a essência do instituto e suas características fundamentais.

O estudo será pautado pela hermenêutica e pela tópica, posto que uma investigação profícua sobre as potencialidades da mediação judicial compatibiliza-se com a concepção contemporânea de racionalidade prática.

As conclusões parciais extraídas ao longo do desenvolvimento do artigo permitirão concluir que a incorporação da mediação ao Sistema de Justiça servirá ao propósito de ampliar o acesso à Justiça e contribuir para a autonomização dos cidadãos na resolução dos seus conflitos.

\section{A MEDIAÇÃo DE CONFLITOS NO NOVO CÓDIGO DE PROCESSO CIVIL}

No que se refere à mediação, o NCPC (Lei $n^{\circ}$ 13.105/2015) avançou significativamente em relação ao Código de 1973. Realmente, enquanto o diploma normativo precedente não trazia qualquer previsão sobre a mediação - embora tratasse da conciliação em dez artigos -, o diploma recém-sancionado menciona a expressamente a mediação em 39 oportunidades diferentes.

A Comissão de Juristas responsável pela elaboração do projeto registrou na Exposição de Motivos a intenção de "converter o processo em instrumento incluído no contexto social em que produzirá efeito o seu resultado. Deu-se ênfase à possibilidade de as partes porem fim ao conflito pela via da mediação ou da conciliação" (ANTEPROJETO DO NOVO CÓDIGO 


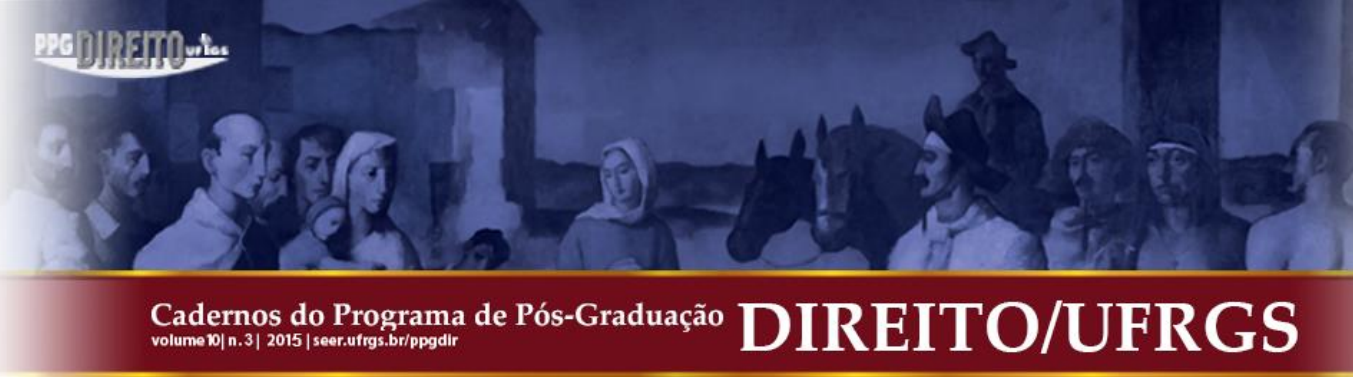

DE PROCESSO CIVIL, 2010, p. 22). A iniciativa foi referendada pelos legisladores pareceristas do projeto, para os quais o tratamento da mediação e da conciliação na Parte Geral do PL representa um avanço importante, sobretudo por conferir a esses mecanismos de resolução de conflitos todo o destaque que modernamente eles têm tido.

A mediação é mencionada pela primeira vez já no artigo $3^{\circ}$ do NCPC, topograficamente localizado no Capítulo I, Livro I da Parte Geral. O caput do artigo enuncia o princípio da inafastabilidade da jurisdição ("não se excluirá da apreciação jurisdicional ameaça ou lesão a direito"), e, logo em seguida, o $\S 2^{\circ}$ aduz que "o Estado promoverá, sempre que possível, a solução consensual dos conflitos". Finalmente, o $\S 3^{\circ}$ determina que a mediação e outros métodos de solução consensual de conflitos “deverão ser estimulados por juízes, advogados, defensores públicos e membros do Ministério Público, inclusive no curso do processo judicial".

A simples leitura da norma processual acima referida permite concluir que o CPC/2015 reconhece natureza jurídica jurisdicional aos mecanismos autocompositivos. Ou seja, a mediação tanto poderá ser ofertada extrajudicialmente como no curso dos processos judiciais, o que é possível pela incorporação das técnicas de pacificação de conflitos.

A conclusão é reforçada pela inclusão dos mediadores e conciliadores judiciais entre os auxiliares da Justiça, nos termos do artigo 149 do NCPC. Dentro do Capítulo III, o diploma destina uma seção inteira, composta por onze artigos, para o regramento das atividades dos mediadores e conciliadores judiciais.

De acordo com o artigo 166, a atuação dos mediadores deverá ser pautada pelos princípios da independência, da imparcialidade, da autonomia da vontade, da confidencialidade, da oralidade, da informalidade e da decisão informada.

Mais adiante, o artigo 168 resguarda o direito das partes a escolher, conjuntamente, um mediador para atuar no processo, que pode ou não ter cadastro no tribunal (artigo 168, $\S 1^{\circ}$ ). Cuida-se de garantia importante, pois o terceiro deve inspirar confiança nos interessados.

$\mathrm{Na}$ condição de auxiliares da Justiça, os mediadores e conciliadores deverão ser remunerados pelos trabalhos desempenhados (artigo 169). A regulamentação do abono variável e das jornadas de trabalho foi atribuída aos Tribunais, que observarão para este fim 


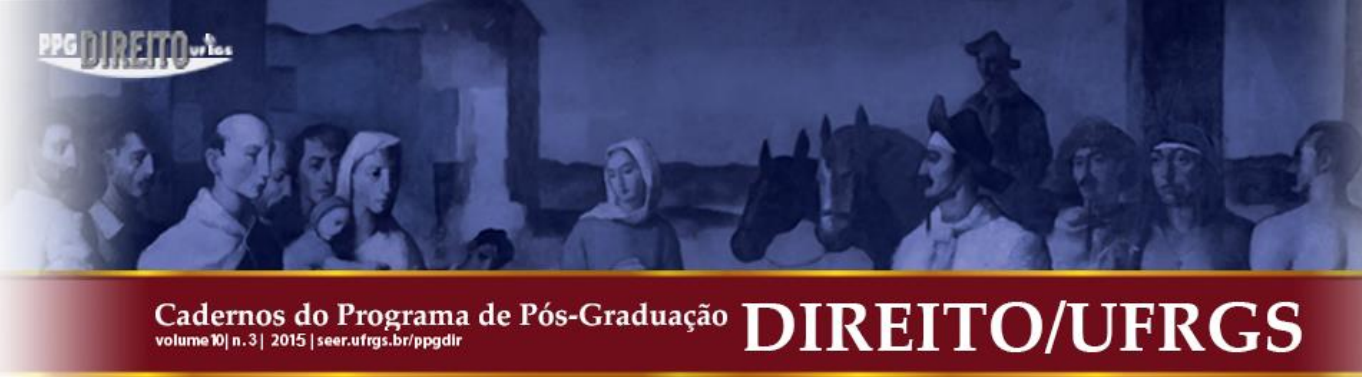

os parâmetros estabelecidos pelo Conselho Nacional de Justiça. ${ }^{1} \mathrm{O}$ trabalho voluntário como mediador também encontra autorização no NCPC, nos termos do $\S 1^{\circ}$ do artigo 169.

Mas apesar dos avanços representados pela institucionalização da mediação pelo Poder Judiciário, é preciso ter cuidado para que o entusiasmo inicial não ofusque as muitas incongruências presentes no texto aprovado. Recomenda-se, como no ditado, ir "devagar com o andor, porque o santo é de barro!”. Vejamos o porquê.

\subsection{A obrigatoriedade da mediação}

O novo diploma processual exige que o autor indique na petição inicial se deseja ou não levar o conflito à mediação ou conciliação. Caso esta informação não esteja presente, o juiz determinará que o autor a emende ou a complete no prazo de 15 dias (artigo 319 c/c 321 do NCPC). No mesmo sentido, o $§ 5^{\circ}$ do artigo 334 fixa que o réu deverá manifestar o seu desinteresse em participar da audiência de mediação, em petição escrita, ao menos 10 dias antes do dia designado para a audiência.

Cumpre redobrar a atenção para análise do artigo $334, \S 4^{\circ}$ e incisos I e II do NCPC. A norma estabelece que a audiência de mediação apenas não será designada se ambas as partes manifestarem, expressamente, o desinteresse pela composição consensual do litígio ou se a natureza da causa inadmitir transação.

Isso significa que embora a norma processual inclua a autonomia da vontade no rol de princípios informadores da mediação, o que ela faz em seguida é esvaziar- lhe o sentido. A primeira impressão transmitida pela leitura do artigo 334 é a de que a mediação foi pensada para servir como obstáculo ao exercício legítimo do direito de ação, atendendo aos propósitos de celeridade do Judiciário - beneficiado com o filtro de admissibilidade das demandas recém-instituído - e aos litigantes de má-fé interessados na procrastinação do julgamento da lide. $^{2}$

\footnotetext{
${ }^{1}$ Interessante notar que poucos Tribunais estaduais já possuem iniciativas legislativas nesse sentido. Uma exceção é o TJ-SP, que encaminhou à apreciação da Assembleia Legislativa, em dezembro de 2013, um PL que regulamenta o exercício das funções de mediadores e conciliadores inscritos nos Centros Judiciários de Solução de Conflitos e Cidadania vinculados ao Núcleo Permanente do referido Tribunal. O projeto estipula jornadas diárias de duas, quatro, seis e oito horas, dentro do expediente forense, limitadas em 16 horas semanais, e abono variável de $\mathrm{R} \$ 40,28$ por hora de trabalho.

${ }^{2}$ A única ressalva diz respeito ao encaminhamento de processo à mediação quando houver pedido de liminar. Nesse sentido, o artigo 303 prevê que se a urgência for contemporânea à propositura da ação, a petição inicial pode limitar-se ao requerimento da tutela antecipada e à indicação do pedido de tutela final. Se o caso for 


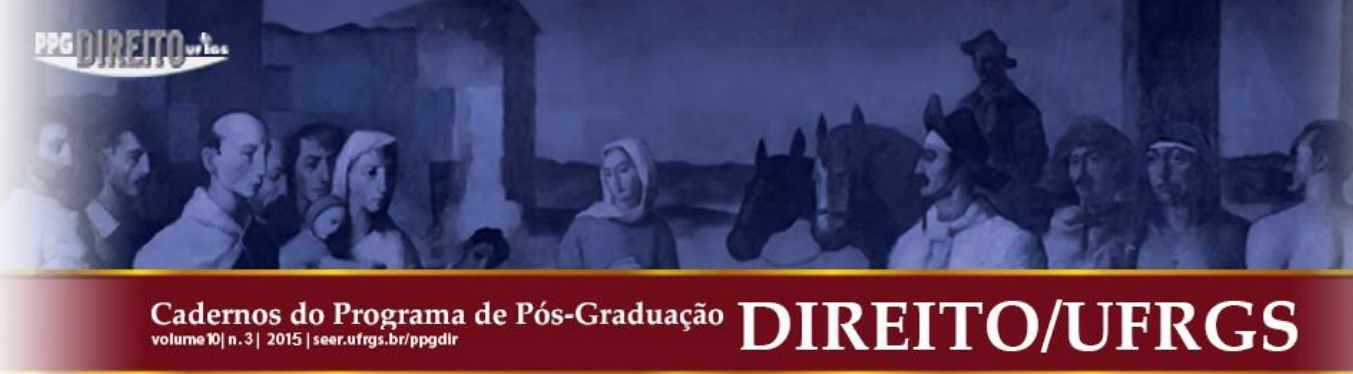

A verdade é que o Código introduziu no sistema jurídico uma espécie de obrigatoriedade mitigada para o processo de mediação, i.e., uma obrigatoriedade presumida e que somente pode ser elidida por meio da anuência concreta dos litigantes.

O não comparecimento injustificado do autor ou do réu à audiência de mediação é considerado ato atentatório à dignidade da justiça, apenado com multa de $2 \%$ (dois por cento) da vantagem econômica pretendida ou do valor da causa, revertida em favor da União ou do Estado (artigo 334, §8º).

Além da regra geral, o NCPC prevê dois casos de obrigatoriedade absoluta da mediação, em que o encaminhamento do processo para o Centro Judiciário de Solução de Conflitos e Cidadania (CEJUSC) independe da concordância prévia das partes.

$\mathrm{O}$ primeiro caso diz respeito às ações de família. Em razão das peculiaridades e da complexidade dos relacionamentos familiares, o Código preceitua que todos os esforços deverão ser empreendidos para que o conflito seja solucionado consensualmente, devendo o juiz dispor do auxílio de profissionais de outras áreas do conhecimento para a mediação e a conciliação. A seguir, o parágrafo único permite, a requerimento das partes, que o magistrado suspenda o processo para que as partes participem de mediação extrajudicial ou de atendimento multidisciplinar.

Quanto à segunda hipótese, o artigo 565 estabelece que nos litígios coletivos envolvendo a posse de imóveis, quando o esbulho ou a turbação alegada na petição inicial houverem ocorrido há mais de ano e dia, o juiz deverá, antes mesmo de avaliar o pedido de liminar, designar audiência de mediação. O Ministério Público será necessariamente intimado para esta audiência, assim como a Defensoria Pública se alguma parte for beneficiária de gratuidade da justiça (artigo $565, \S 2^{\circ}$ ).

\subsection{A presença dos juízes na sessão de mediação}

O $\S 1^{\circ}$ do artigo 334 dispõe que os mediadores e os conciliadores devem atuar, necessariamente, nas “audiências” destinadas à autocomposição.

Conforme destacam Rodrigo Reis Mazzei e Bruno Pereira Marques, o processo de mediação não acontece, a rigor, em audiências, mas em sessões. A dúvida, portanto, é se 


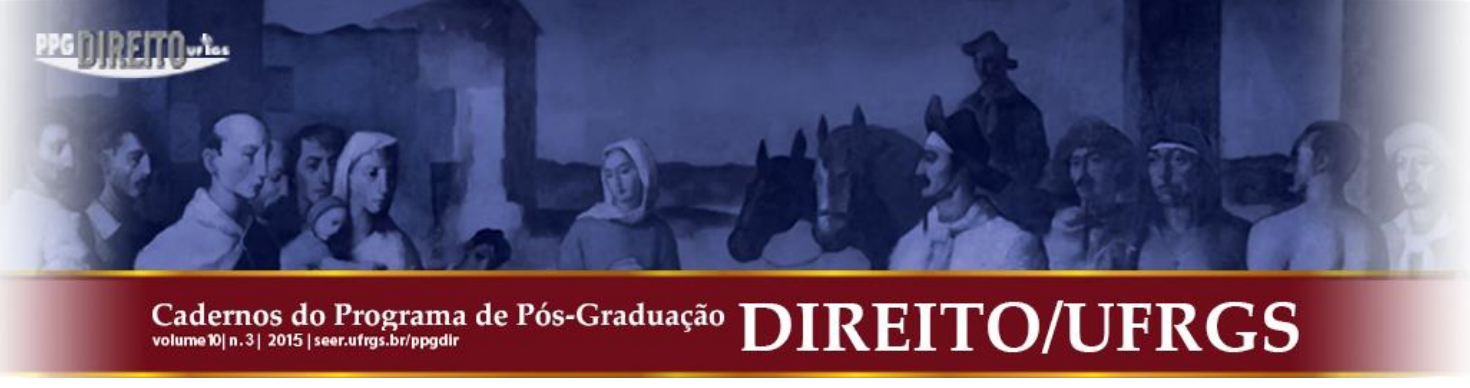

serão inscritos no cadastro nacional, sendo-lhes vedado exercer a advocacia nos juízos em que desempenhem suas funções. Debruçando-se sobre a nova regra, Fernanda Tartuce questiona:

\begin{abstract}
[...] se o mediador inscrito no Tribunal não poderá advogar no juízo em que se inscreveu, como poderá sobreviver?

Imaginemos, para ilustrar, uma situação concreta: atuo como advogada no Departamento Jurídico do XI de Agosto, entidade da Faculdade de Direito da USP que presta assistência à população carente desde 1919 e tem processos tramitando em praticamente todos os foros da Capital paulista.

Decido fazer o cadastro como mediadora no Tribunal de Justiça de São Paulo e aguardo ser escolhida pelas partes ou nomeada para algum feito por força de distribuição.

Caso seja chamada a atuar como mediadora em feito que tramita em determinada Vara, precisarei verificar se tenho algum processo em trâmite ali; sendo a resposta positiva, deverei me reconhecer impedida de atuar e terei que declinar. Esta situação é apropriada? Se atuo como advogada em um feito de natureza diversa, com litigantes diferentes, não sou apta a atuar em outro processo com diferentes envolvidos pelo simples fato de tramitarem no mesmo juízo? (TARTUCE, 2014, p. $14)$.
\end{abstract}

Apesar da boa intenção do legislador, a norma analisada desencoraja os novos advogados a se cadastrarem no rol de mediadores e conciliadores judiciais. Outrossim, importante registrar que o impedimento criado não segue a mesma lógica dos impedimentos encartados no Estatuto da advocacia.

\title{
1.4 A imparcialidade do mediador
}

A quarta crítica diz respeito ao princípio da imparcialidade na atuação do mediador. Conforme previsão contida no artigo 166, a atuação dos mediadores deve observar o princípio da imparcialidade, sendo que a inobservância desse dever enseja a exclusão do profissional do cadastro do tribunal (artigo 173, inciso I).

O princípio da imparcialidade costuma ser arrolado como um atributo indispensável do mediador, a quem cumpriria manter uma postura de equidistância entre as partes e seus interesses. $^{3}$ Assim, os mediadores deveriam atuar somente para auxiliar as partes no restabelecimento do diálogo, e, se possível, na autocomposição do litígio.

Entretanto, importa observar que a exigência de imparcialidade dos serventuários da justiça, mais do que preocupação com o favorecimento das partes, constitui-se em

\footnotetext{
${ }^{3}$ Nesse sentido, Petrônio Calmon apresenta princípio da imparcialidade como "o direito das partes a um método de mediação que lhes sirva de um modo justo e equitativo e a contar com mediadores que se abstenham de todo prejuízo ou favoritismo" (CALMON, 2013, p. 117).
} 


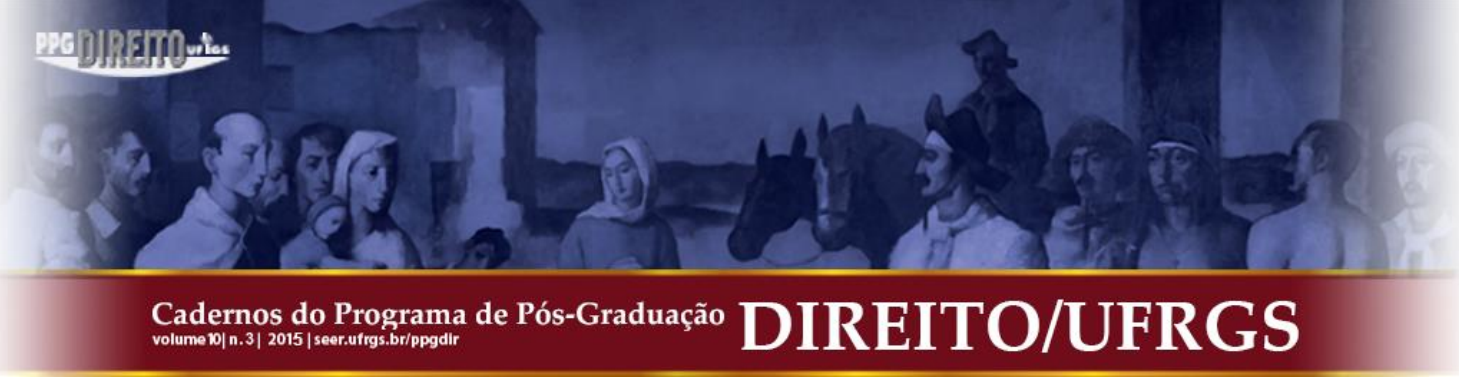

manifestação de poder e autoridade Nesse sentido, discorrendo sobre a simbologia da imparcialidade do juiz, Geovany Cardoso Jeveaux é enfático:

\begin{abstract}
[...] se se considerar o sistema jurídico mais que um conjunto de normas ou instituições, mas um fenômeno de "partes em comunicação", onde estão pressupostos uma interação (troca de mensagens), um relato (informação contida na mensagem) e um cometimento (informação sobre como encarar a mensagem), a atuação do Estado-juiz como terceiro comunicador - além dos dois primeiros, que são as partes, as quais estarão sujeitas à decisão - ocorre numa situação de controle comunicativo para tornar a decisão um instrumento de suscitação de obediência, justamente através de um domínio e de uma estratégia de domínio (JEVEAUX, 1999, p. 8).
\end{abstract}

Ao contrário dos magistrados, o mediador não dispõe dos poderes e prerrogativas inerentes à função jurisdicional, razão pela qual privar-lhe de qualquer possibilidade de aproximação das partes ou de intervir para reequilibrar as relações de forças entre elas, equivaleria a esvaziar de sentido o seu papel. A esse propósito, Fabiana Marion Spengler anotou que "enquanto o juiz é pensado, nos sistemas modernos, como o 'nec utrum, nem um, nem outro, nem isto nem aquilo', justamente neutro, o mediador deve ser 'isto e aquilo', deve perder a neutralidade e perdê-la até o fim" (SPENGLER, 2010, 343).

$\mathrm{O}$ argumento da autora é relevante, ainda que a observação sobre o abandono completo da mediação deva ser vista cum grano salis. $\mathrm{O}$ mediador deve perceber as diferenças comuns aos conflitantes e trabalhar a partir desse ponto, possibilitando a retomada da comunicação. Como ensina o professor Guilherme Assis de Almeida:

\begin{abstract}
O trabalho da mediação tem como ponto de partida o reconhecimento do "valor social" de todos aqueles envolvidos em determinado conflito. Importante ter claro que, devido ao fato de vivermos em uma verdadeira "sociedade de indivíduos" (no sentido antropológico do termo), o exercício do diálogo, da compreensão de uma lógica do existir diversa da nossa não é uma tarefa a que estejamos habituados. Portanto, exige de todo aquele que se dedique ao trabalho de mediação uma atitude de introspecção e sensibilidade, capaz de perceber a melhor forma de expressar o seu reconhecimento por todos aqueles envolvidos no conflito. Essa atitude inicial do mediador a favorece a criação de um ambiente dialógico. Único espaço possível para que se possa estabelecer um processo de reconhecimento mútuo das pessoas que participam do conflito (ALMEIDA, 2014, p. 22).
\end{abstract}

Os mediadores precisam de liberdade para se inserir entre as partes, embora não lhes caiba assumir uma postura necessariamente equidistante. Espera-se que eles possam proteger as partes mais vulneráveis do conflito, conter as pretensões dos mais influentes e corrigir as desigualdades de poder. 


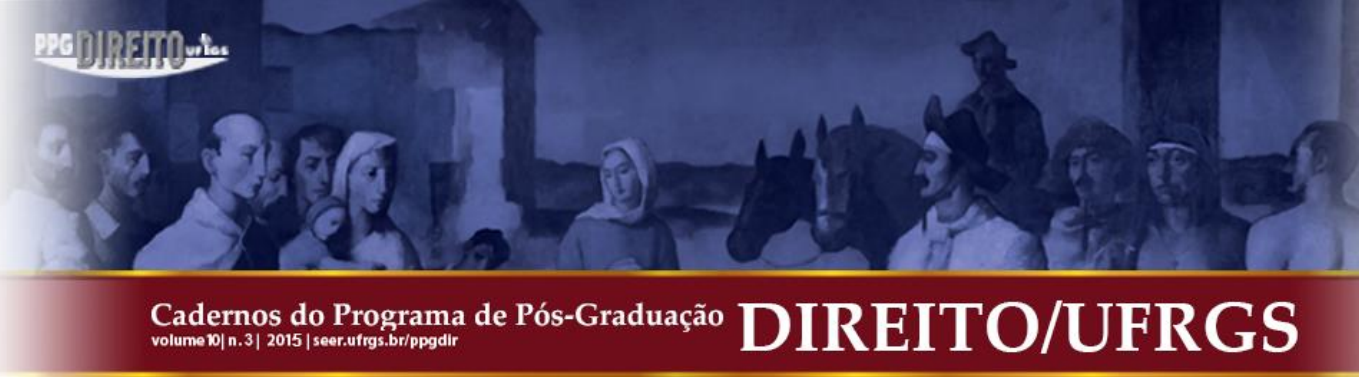

Nesse sentido, caso prevaleça a literalidade do artigo 173, I do NCPC, o mediador que, por definição, precisa abrir mão de sua imparcialidade para restabelecer o liame comunicacional entre as partes - deverá orientar-se pelos mesmos ditames de imparcialidade impostos aos magistrados, sob pena de exclusão dos quadros de mediadores dos tribunais.

Ou seja, ao mesmo tempo em que o NCPC reconhece, surpreendentemente, a natureza jurisdicional dos mecanismos consensuais e espraia previsões normativas sobre a mediação ao longo de todo o texto, ainda hesita em que os mediadores adotem uma postura de parcialidade quando necessário. O legislador rendeu homenagens à mediação, mas conservou-a sob a rédea curta dos mesmos princípios norteadores da atividade jurisdicional. ${ }^{4}$

Trata-se de um aspecto polêmico da positivação do instituto e que dará margem a amplos debates nos próximos anos. Aconselha-se que a aplicação dos motivos de suspeição arrolados no artigo 145, inciso II, do novo diploma processual seja feita com as cautelas devidas, para preservar as características e a vocação pacificadora da mediação.

\subsection{As sessões virtuais de mediação}

Finalmente, importa observar que o Código prevê a possibilidade de realização de audiências de conciliação e mediação por meio eletrônico no (artigo 334, § $7^{\circ}$ ).

A realização de sessões virtuais de mediação ainda provoca desconfortos, pois suprime o caráter pessoal das negociações, conhecido como "face-to-face mediation". Por outro lado, muitos já se convenceram da conveniência do método, na medida em que reduz os custos operacionais e conecta pessoas localizadas em diferentes partes do mundo.

Em que pese aos argumentos contrários, o processo de mediação eletrônica parece adequar-se bem aos novos tempos. Os benefícios do rompimento das barreiras geográficas, a acessibilidade que proporciona às pessoas com deficiências físicas, a celeridade do rito, as

\footnotetext{
${ }^{4}$ A questão da imparcialidade do mediador consistiu em ponto central de atenção das autoras Sara Cobb e Janet Rifkin no emblemático artigo "Practice and Paradox: Deconstructing neutrality in mediation". As professoras estadunidenses afirmam que embora conceitos como imparcialidade e neutralidade sejam pontos centrais na teoria e prática da mediação, cultuados como um antídoto contra o preconceito e condição sine qua non para a preservação do contexto comunicacional em que queixas possam ser ouvidas e acordos mutuamente construídos, contraditoriamente seus conceitos permanecem indefinidos pelas organizações profissionais e pouco debatidos nos círculos escolares. Após analisar as definições de mediação usualmente empregadas no campo da mediação (neutralidade como sinônimo de imparcialidade ou de equidistância), assim como suas implicações concretas, as autoras concluem que tais concepções devem ser entendidas como prática no discurso (COBB; RIFKIN, 1991, p. $35)$.
}

Cadernos do Programa de Pós-Graduação em Direito PPGDir./UFRgS | Edição Digital | Porto Alegre | Volume X | Número 3 | 2015 | P. 316 -337 


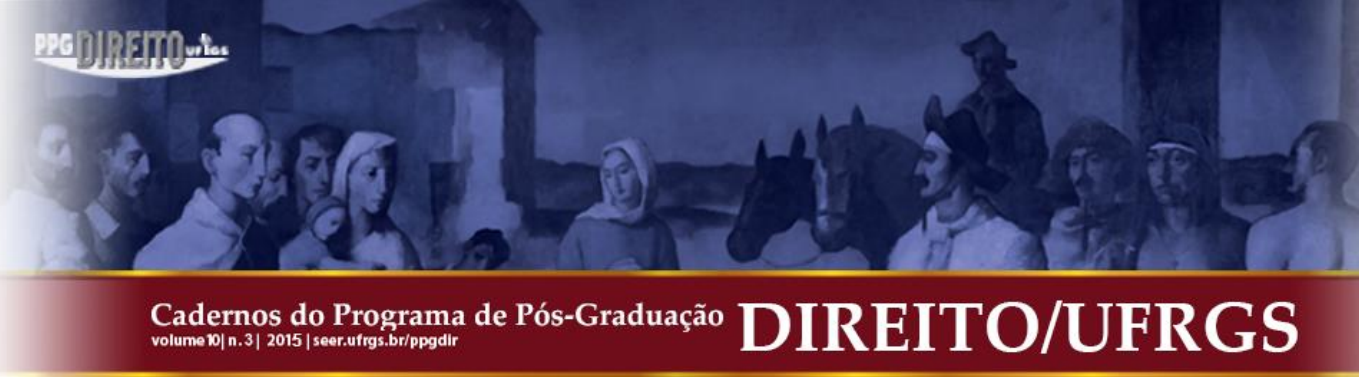

módicas despesas econômicas suportadas pelos usuários, tudo isso justifica a aposta do Código de 2015 nessa ferramenta.

O ponto de preocupação relacionado às plataformas online reside na asseguração da higidez do procedimento e das cláusulas de garantia das partes. Os sistemas de videoconferência dos tribunais deverão avalizar a identidade dos intervenientes, certificando a titularidade e autenticidade da firma. Além disso, os mediadores deverão desenvolver habilidades específicas para interpretar à distância os sentimentos das partes e a ocorrência de vícios no consentimento.

Por fim, cumpre dizer que a mediação virtual já é amplamente utilizada em países como a Alemanha, Estados Unidos, Holanda e Argentina. Tanto é assim que muitas empresas de tecnologia se especializaram no desenvolvimento de softwares próprios para o desenvolvimento das sessões online. ${ }^{5}$

\section{A LEI DE MEDIAÇÃO (LEI N. 13.140/2015)}

Além do NCPC e da Resolução $n^{\circ}$ 125/2010 do Conselho Nacional de Justiça, a Presidente da República sancionou, em 29 de junho de 2015, a Lei $n^{\circ}$ 13.140/2015, que dispõe sobre a mediação entre particulares como meio alternativo de solução de controvérsias e sobre a autocomposição de conflitos no âmbito da administração pública. ${ }^{6}$

$\mathrm{O}$ artigo $2^{\circ}$ da lei recém-aprovada conceitua a mediação como o "processo conduzido por terceiro imparcial, com o objetivo de auxiliar as partes a identificar ou desenvolver soluções consensuais". Em sintonia com o NCPC, a Lei n 13.140/2015 encampa o princípio da imparcialidade do mediador, estabelecendo no parágrafo único do artigo $5^{\circ}$ que o terceiro tem o dever de revelar às partes, antes da aceitação da função, qualquer fato ou circunstância que possa suscitar dúvida justificada em relação à sua imparcialidade para mediar o conflito.

Novamente, o legislador cuidou de enfatizar a exigência de imparcialidade na condução do procedimento, embora o conteúdo desta exigência tenha permanecido sem

\footnotetext{
${ }^{5}$ Além dos sites destinados à mediação online, em junho de 2014, uma empresa desenvolveu recentemente o primeiro aplicativo global voltado à resolução de conflitos entre empresas e clientes, o "Youstice". Trata-se de um projeto bastante interessante e que certamente servirá de exemplo ao desenvolvimento de outros na mesma linha. Disponível em: <http://www.youstice.com/pt/>. Acesso em 18 nov. 2014.

${ }^{6} \mathrm{O}$ anteprojeto da lei de Mediação Civil, de autoria do senador Ricardo Ferraço, consolida as sugestões dos professores Humberto Dalla Bernardina de Pinho, Trícia Navarro Xavier Cabral e Gabriela Asmar sobre o tema. 


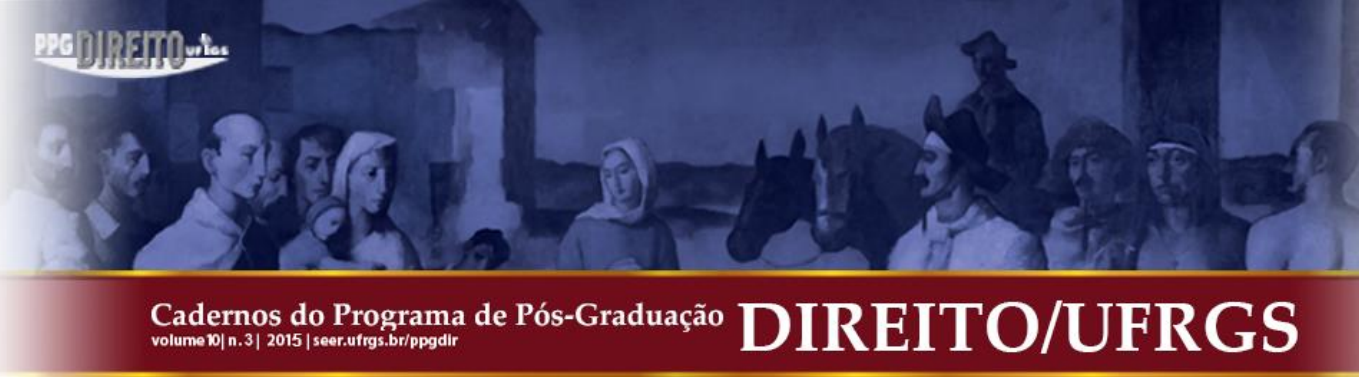

definição normativa. Ou seja, um significante-chave do conceito legislado de mediação carece de significado unívoco e facilmente identificável.

Consequentemente, cumprirá aos cursos de formação de mediadores, à jurisprudência dos tribunais e aos círculos universitários encontrar uma definição razoável para a famigerada imparcialidade, compatíveis com o exercício da função.

O anteprojeto da Lei da Mediação distinguia entre mediação judicial e extrajudicial a partir do critério da iniciativa da escolha do mediador. Nessa linha, a mediação seria judicial quando os mediadores fossem escolhidos pelo Poder Judiciário e extrajudicial quando a escolha do mediador ou da instituição de mediação privada pertencesse às partes (artigo $6^{\circ}$ do PL n $\left.{ }^{\circ} 8.046 / 2010\right)$.

Ainda que a lei não tenha mantido a distinção conceitual entre os dois tipos de mediação, é possível inferi-la a partir da leitura conjugada de seus artigos $9^{\circ}, 11,12$ e 25 . De acordo com o artigo $9^{\circ}$, qualquer pessoa capaz e que desperte a confiança das partes pode atuar como mediador extrajudicial, independentemente de integrar conselho de classe ou associação. Por outro lado, o artigo 11 estabelece como requisitos cumulativos para o exercício da função de mediador judicial: (a) dois anos de graduação em curso de ensino superior de instituição reconhecida pelo Ministério da Educação; e (b) capacitação em escola ou instituição de formação de mediadores reconhecida pela Escola Nacional de Formação e Aperfeiçoamento de Magistrados (ENFAM) ou pelos tribunais.

Nos termos do artigo 12, apenas os mediadores inseridos no cadastro dos tribunais serão considerados habilitados e autorizados a atuar em mediação judicial. Finalmente, o artigo 25 estatui que a designação dos mediadores para o processo independe da prévia aceitação das partes, exceto em casos de impedimento e suspeição (artigo $5^{\circ}$ ).

Veja-se que os artigos 12 e 25 da Lei $n^{\circ}$ 13.140/2015 proíbem a escolha do mediador que irá atuar no processo de mediação judicial, ao contrário do que dispõe o artigo $168, \S \S 1^{\circ}$ e $2^{\circ}$, do NCPC, capitulado em Seção destinada ao regramento dos conciliadores e mediadores judiciais. In verbis:

Art. 168. As partes podem escolher, de comum acordo, o conciliador, o mediador ou a câmara privada de conciliação e de mediação.

$\S 1^{\circ}$. O conciliador ou mediador escolhido pelas partes poderá ou não estar cadastrado no tribunal.

$\S 2^{\circ}$. Inexistindo acordo quanto à escolha do mediador ou conciliador, haverá distribuição entre aqueles cadastrados no registro do tribunal, observada a respectiva formação. 


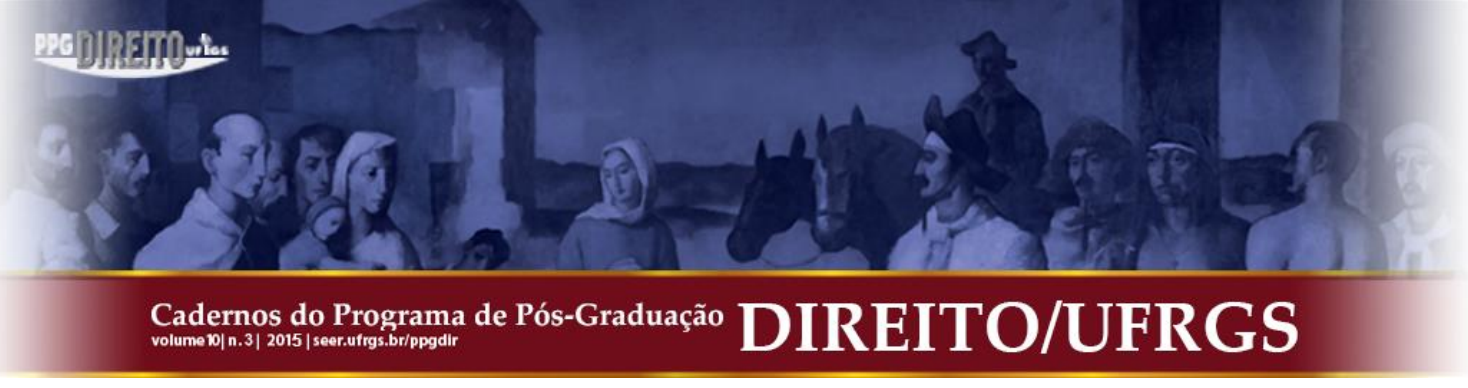

Diante da antinomia entre as normas, poder-se-ia argumentar que o artigo 168 e $\S \S 1^{\circ}$ e $2^{\circ}$ do NCPC foram precocemente derrogados - ainda no período de vacatio legis - pelo advento da Lei de Mediação Civil. Por essa linha de raciocínio, o mediador responsável por conduzir a mediação seria designado exclusivamente a partir de uma distribuição alternada e aleatória, nos moldes descritos no artigo $167, \S 2^{\circ}$ da lei processual civil.

Contudo, essa não é a melhor solução interpretativa para o problema, pois o sucesso da mediação depende da relação de empatia e confiabilidade estabelecida entre as partes e o mediador. A distribuição mecânica dos processos aos profissionais cadastrados nos tribunais corrompe a essência do instituto e interfere indevidamente na autonomia de escolha dos interessados.

O caminho para a compatibilização entre as normas colidentes é acessado pela teoria do diálogo das fontes, idealizada pelo jurista alemão Erik Jayme. Segundo defende o autor, as sociedades pós-modernas convivem com múltiplas fontes legislativas vocacionadas à regulamentação dos mesmos fatos. Essa constatação torna-se mais evidente no campo do direito privado, onde os códigos generalistas concorrem com os microssistemas de regulação, como o Estatuto da Criança e do Adolescente, o Código de Defesa do Consumidor e tantos outros. $^{7}$

Para lidar com a nova realidade normativa, Jayme propõe a substituição do antigo mecanismo de exclusão de normas incompatíveis por um mecanismo de aplicação simultânea, coordenada e sistemática de leis principais e coexistentes no sistema.

Como explica Cláudia Lima Marques (2008, p. 44):

\begin{abstract}
Muda-se assim o paradigma: da retirada simples (revogação) de uma das normas em conflito do sistema jurídico ou do 'monólogo' de uma só norma (a comunicar a solução justa), à convivência destas normas, ao 'diálogo' das normas para alcançar a sua ratio, a finalidade visada ou narrada em ambas. Este atual e necessário 'diálogo das fontes' permite e leva à aplicação simultânea, coerente e coordenada das plúrimas fontes legislativas convergentes com finalidade de proteção efetiva.
\end{abstract}

\footnotetext{
7 Jurista alemão e catedrático de Direito Internacional Privado, Direito Comparado e Direito Civil da Universidade de Heidelberg, Erik Jayme empregou o termo "Diálogo das Fontes" pela primeira vez durante curso ministrado em Haia no ano de 1995. Quanto ao sentido do termo, o autor aduz o seguinte: "O 'diálogo das fontes' significa que decisões de casos da vida complexos são hoje o somar, o aplicar conjuntamente, de várias fontes (Constituição, Direitos Humanos, direito supranacional e direito nacional). Hoje não mais existe uma fixa determinação de ordem entre as fontes, mas uma cumulação destas, um aplicar lado a lado. Os direitos humanos são direitos fundamentais, mas somente às vezes é possível deles retirar efeitos jurídicos precisos" (JAYME, jul./set. 2000, p. 289-293).
} 


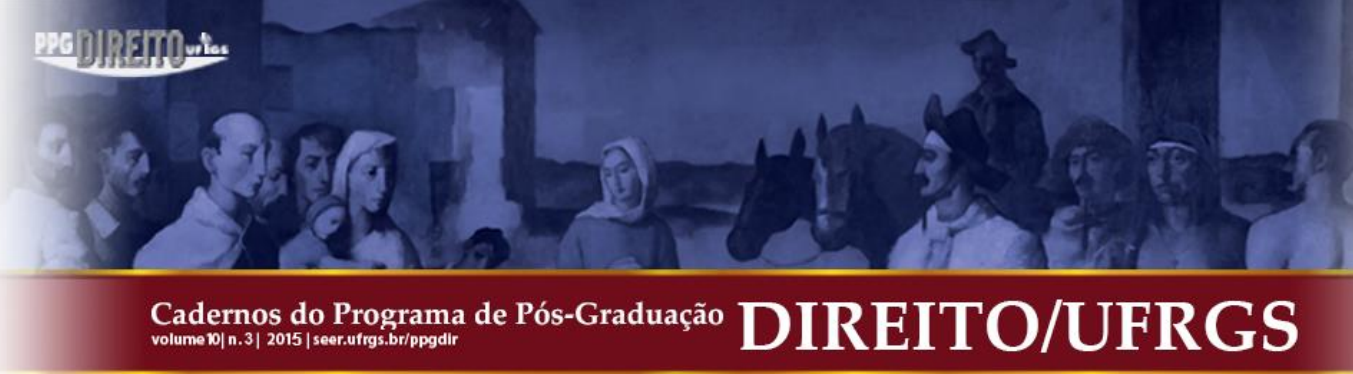

O contrato poderá prever, ainda, a penalização da parte signatária que se recusar a comparecer ao primeiro encontro de mediação. Caso o contrato silencie quanto à sanção cabível, aplicar-se-á a norma do artigo $22, \S 2^{\circ}$, inciso IV da lei.

O capítulo II da Lei de Mediação versa sobre a autocomposição de conflito sem que for parte o Poder Público.

Nos termos do artigo 32, a União, os Estados, o Distrito Federal e os Municípios poderão criar câmaras de prevenção e resolução administrativa de conflitos, no âmbito dos órgãos da Administração Pública, com competência para I - dirimir conflitos entre órgãos e entidades da administração pública; II - avaliar a admissibilidade da autocomposição em conflitos envolvendo particulares e pessoa jurídica de direito público; e III - promover a celebração de termo de ajustamento de conduta.

A criação das câmaras de prevenção e resolução de conflitos não representa propriamente uma inovação no âmbito da União Federal, uma vez que a Advocacia-Geral da União instituiu, ainda no ano de 2007, a Câmara de Conciliação e Arbitragem da Administração Federal (CCAF).

$\mathrm{O}$ ponto de destaque consiste na possibilidade de as câmaras avaliarem a admissibilidade de composição consensual dos conflitos envolvendo particulares e pessoas jurídicas de direito público. Cuida-se de uma política embrionária de instituição da mediação na esfera administrativa, cumprindo às câmaras a definição das políticas de conciliação no âmbito de sua competência. O permissivo legal estende-se inclusive para as demandas coletivas, nos termos do artigo 33 da lei.

Se bem utilizada, essa ferramenta permitirá que as matérias já pacificadas pelos tribunais e as demandas repetitivas sejam sanadas consensualmente, reduzindo a canalização de processos para o Judiciário.

As câmaras funcionarão dentro dos órgãos da Advocacia Pública (Advocacia-Geral da União, Procuradoria Geral do Estado e Procuradoria do Município) e terão autonomia para definir requisitos qualitativos e quantitativos para o encaminhamento de propostas à mediação, a fim de que sirvam como baliza para a atuação dos Procuradores Públicos.

Portanto, a Lei de Mediação estendeu os horizontes da autocomposição no âmbito do Direito Administrativo. O legislador encampou a doutrina contemporânea da ductilidade constitucional amplamente difundida por Gustavo Zagrebelski, segundo a qual pluralismo 


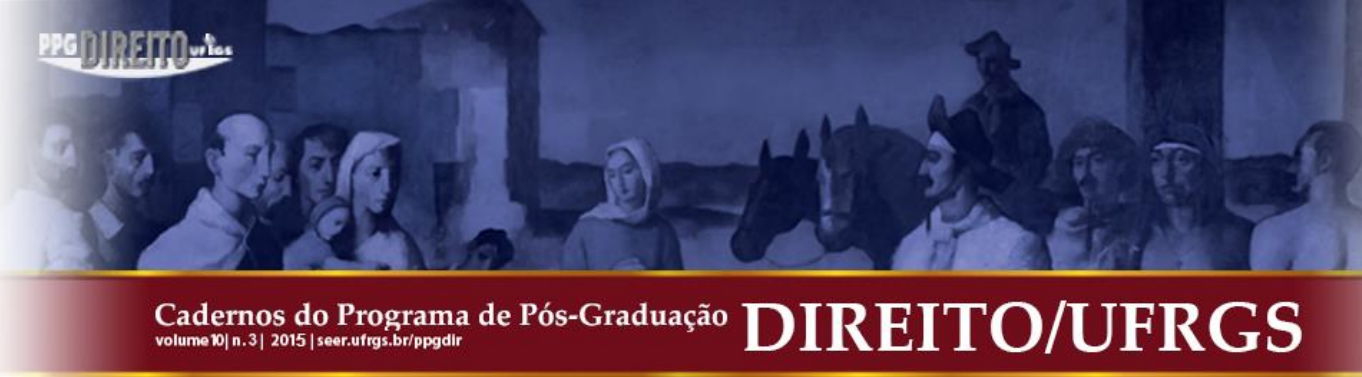

jurídico inspira a superação da dicotomia entre Poder Público e cidadãos, sugerindo uma aproximação pelo diálogo. Nas palavras do autor:

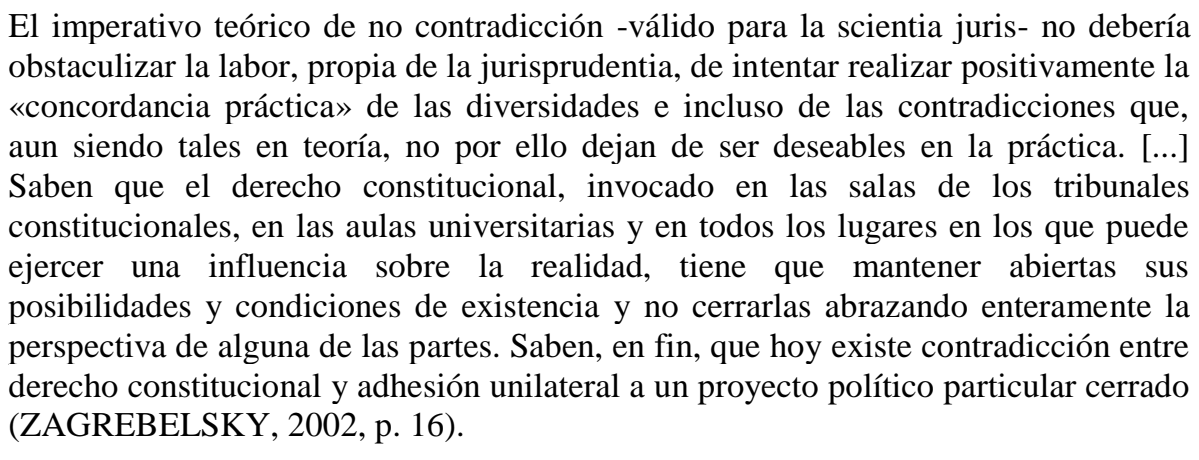

Lamenta-se apenas que as disposições dos incisos II e III do caput do artigo 32 não se apliquem às controvérsias envolvendo tributos administrativos da Receita Federal e aos créditos inscritos em dívida ativa da União (artigo 38, inciso I). Os acordos em torno dos executivos fiscais contribuiriam sobremaneira para desafogar os foros das Justiça Federal e Estadual, onde milhares de processos se arrastam por anos sem perspectiva de solução.

Nos termos do artigo 34, a instauração de procedimento administrativo para a resolução consensual do conflito suspende a prescrição. Considera-se instaurado o procedimento quando o órgão ou entidade pública emitir juízo de admissibilidade, retroagindo os efeitos dessa decisão à data de formalização do pedido $\left(\S 1^{\circ}\right)$.

Além das regras gerais sobre o funcionamento das câmaras a Lei $n^{\circ} 13.140 / 2015$ também previu um regramento específico para a pacificação consensual de conflitos na esfera da administração pública federal.

$\mathrm{O}$ artigo 35 da lei consagrou a figura da transação por adesão. $\mathrm{O}$ instituto possibilita que as demandas repetitivas sejam solucionadas internamente a partir da observância de certos parâmetros fechados e vinculativos. A proposta de acordo apenas será possível se fundamentada em autorização expressa do Advogado-Geral da União, com base em jurisprudência pacífica dos Tribunais Superiores ou em parecer do Advogado-Geral da União aprovado pelo Presidente da República.

Debruçando-se sobre a nova previsão normativa, o desembargador do Tribunal Regional da $4^{\mathrm{a}}$ Região Paulo Afonso Brum Vaz adverte que não é correto falar em autocomposição no sentido estrito do termo, senão em uma modalidade contratual que 


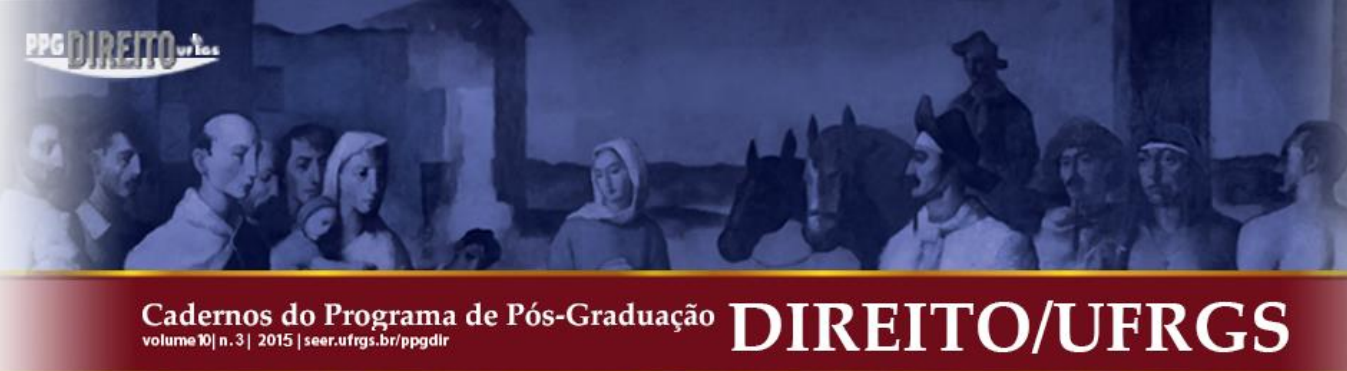

transformou o direito em mercadorias (law shopping) e os cidadãos em consumidores de direito (Supiot). Nas suas palavras:

\begin{abstract}
São os contratos cujo objetivo primordial não é mais trocar determinados bens nem selar uma aliança entre iguais, mas legitimar o exercício de um poder e a subordinação. Nos acordos em que figura como parte o Poder Público, com propostas fechadas e condicionamentos administrativos ditados unilateralmente, a partir de uma lógica de eficiência, algo como um all or nothing, tem-se uma espécie de contrato de dependência dirigido, trazendo consigo, ostensivamente, o arbítrio, o poder e a subordinação (VAZ, 2014, p. 6-7).
\end{abstract}

De toda sorte, não se ignora que a norma servirá ao propósito de inibir a judicialização das demandas repetitivas, permitindo que os cidadãos adiram às condições previamente estabelecidas em matérias já pacificadas pelas Cortes. Conforme observa Brum Vaz, o sucesso da transação por adesão dependerá de fatores como a efetiva pacificação das demandas recorrentes pelos Tribunais Superiores, uma atuação eficiente do Advogado-Geral da União na concessão de autorização ou emissão de pareceres favoráveis à composição e, finalmente, a qualidade dos requisitos e das condições estipuladas para a resolução interna dos conflitos (VAZ, 2014, p. 7).

Importante observar que a formalização de resolução administrativa destinada à transação por adesão não implica em renúncia tácita à prescrição, nem tampouco à sua interrupção ou suspensão (artigo $35, \S^{\circ}$ ).

Caso a controvérsia jurídica envolva órgãos ou entidades de direito público da administração federal, a AGU deverá realizar a composição extrajudicial do conflito. Nessa hipótese, caso não haja acordo entre as partes, caberá ao Advogado-Geral da União dirimir o conflito.

Nos termos do artigo 39, a propositura de ação judicial em que figurem concomitantemente nos polos ativo e passivo órgãos ou entidades de direito público que integrem a administração pública federal dependerá de autorização prévia do Advogado-Geral da União.

O artigo 40 versa sobre a responsabilidade dos servidores e empregados públicos que participarem do processo de composição extrajudicial, aduzindo que somente poderão ser responsabilizados civil, administrativa ou penalmente aqueles que, mediante dolo ou fraude, receberem qualquer vantagem patrimonial indevida, permitirem ou facilitarem sua recepção por terceiros. 


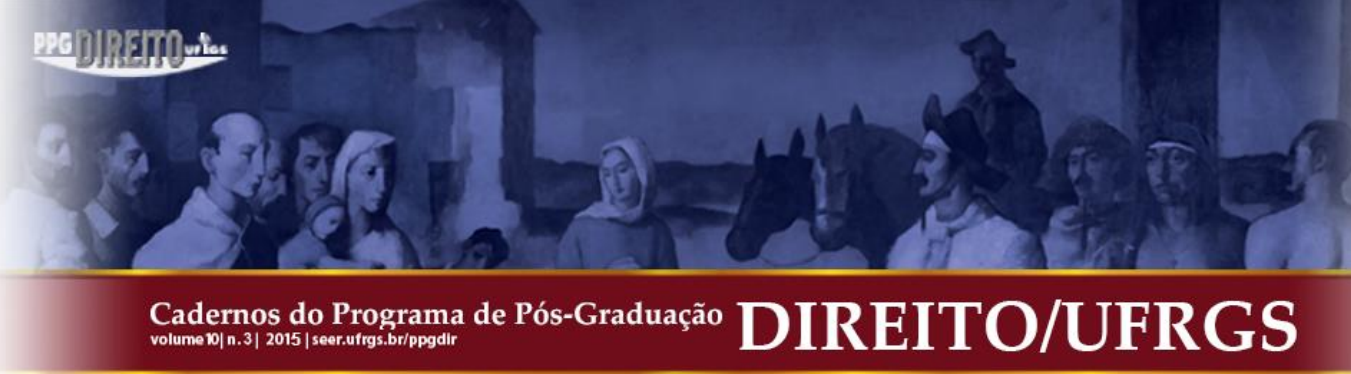

A regra é polêmica, pois afasta a caracterização dos crimes funcionais culposos na autocomposição. Ainda assim, parece que a escolha do legislador em premiar a boa-fé dos que acreditam nas formas autocompositivas foi acertada. A condenação de procuradores por culpa na tabulação de acordos poderia inibir as iniciativas de composição, sombreando-as com o temor de represálias administrativas ou de responsabilização criminal por eventuais danos causados ao Poder Público.

Finalmente, interessante observar que o artigo 46 adere à decisão do NCPC de permitir que a mediação seja conduzida por meio eletrônico, facultando-se que a parte domiciliada no exterior participe da mediação nos termos da lei. No âmbito da Justiça Federal, a conciliação virtual é praticada desde 2012 e permite que partes localizadas em diferentes pontos do globo se conectem de forma eficaz e segura.

\section{CONCLUSÃO}

A aprovação da Lei de Mediação Civil no marco normativo do NCPC representa uma promessa de virada revolucionária na forma de tratamento dos conflitos. Lançando-se sobre ela um olhar prospectivo, vislumbra-se o paulatino empoderamento dos cidadãos e a possibilidade de que assumam, efetivamente, o papel de protagonistas na solução consensual de desavenças. Para que isto seja possível, contudo, será necessário que os magistrados em geral - e não só eles, mas também advogados, Defensores Públicos, MP, serventuários da Justiça - reconheçam a importância dos mecanismos consensuais e cedam espaço para que as partes dialoguem e busquem conjuntamente o entendimento.

As inovações legislativas representam um primeiro passo importante, mas a caminhada dependerá, sobretudo, da mudança cultural dos cidadãos e dos operadores do direito.

Ainda há muita desconfiança em torno da incorporação da mediação do Poder Judiciário. Os céticos alertam que a institucionalização do consenso, menos do que educar para a autonomia cidadã, atuará como barreira de contenção e engessamento dos instrumentos populares de empoderamento social.

Realmente, abundam indícios nesse sentido. Vejam-se, por exemplo, a obrigatoriedade da mediação, a exigência de imparcialidade do mediador e a intenção da nova lei de vincular as partes ao mediador escolhido por distribuição mecânica, dentre tantos outros fatores 


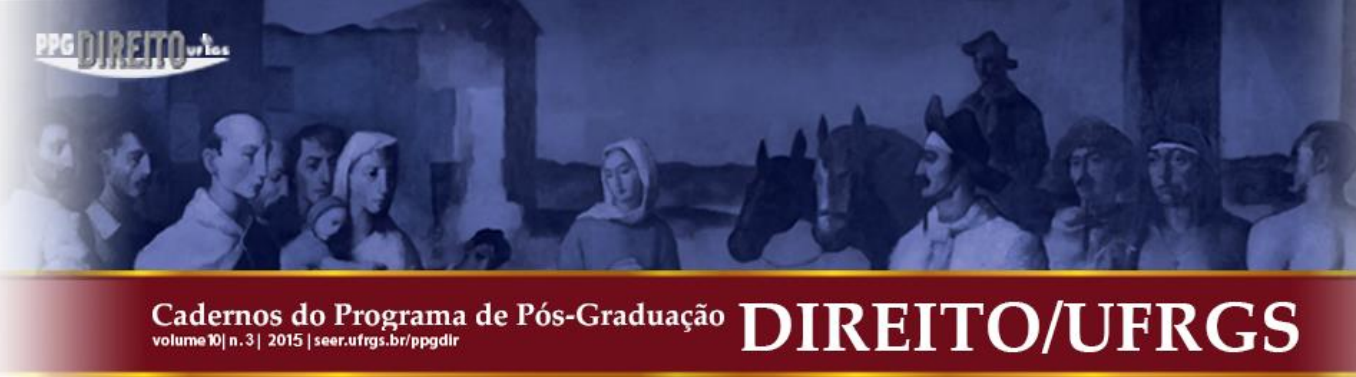

legislativos e materiais que comprometem a credibilidade da mediação realizada no Judiciário.

Mas há o outro lado. Quando, ainda que implicitamente, a legislação proíbe os magistrados de participarem das sessões de mediação, ela justamente resguarda a esfera de liberdade dos cidadãos contra as interferências indevidas. O que se vê, hoje em dia, é que muitos juízes tomam para si a tarefa de mediar conflitos, e quando esta mediação resulta infrutífera, acabam retomando o curso do processo adjudicatório sem esboçar preocupação com os impedimentos éticos e morais que o circundam.

Nesse sentido, a regulamentação da mediação servirá não apenas para educar os cidadãos para o exercício dos direitos, mas especialmente para conter o arbítrio dos magistrados na condução dos processos. Note-se que os conflitos mais importantes - que envolvem laços sociais duradouros - serão solucionados por mediadores, cuja atuação será pautada por princípios de independência e confidencialidade.

Acrescente-se que o estímulo à mediação deverá ser criterioso, a fim de conter abusos e adesões forçosas ou involuntárias aos acordos. É imprescindível que as partes sejam esclarecidas sobre os ganhos advindos da mediação, porém não devem sofrer pressões para participar de processos alternativos, nomeadamente se o caso concreto indicar que as motivações de fundo daquele conflito são inegociáveis. Igualmente, cumpre garantir às partes um ambiente favorável a composições espontâneas, livre de toda sorte de influências, imposições ou coação; as soluções devem ser satisfatórias para os participantes, observandose as peculiaridades e os anseios dos envolvidos.

Em resumo, uma análise circunspecta da mediação judicial demonstra que os riscos inerentes à institucionalização não ofuscam suas vantagens. Nutre-se o anseio de que os mecanismos alternativos auxiliem o Judiciário a solucionar qualitativamente os conflitos por meio do resgate da comunicação e do reconhecimento do protagonismo dos atores sociais.

O caminho será longo até que todos se deem conta da importância da construção de consensos para a pacificação social, mas é reconfortante saber que a Justiça brasileira caminha na direção certa. 


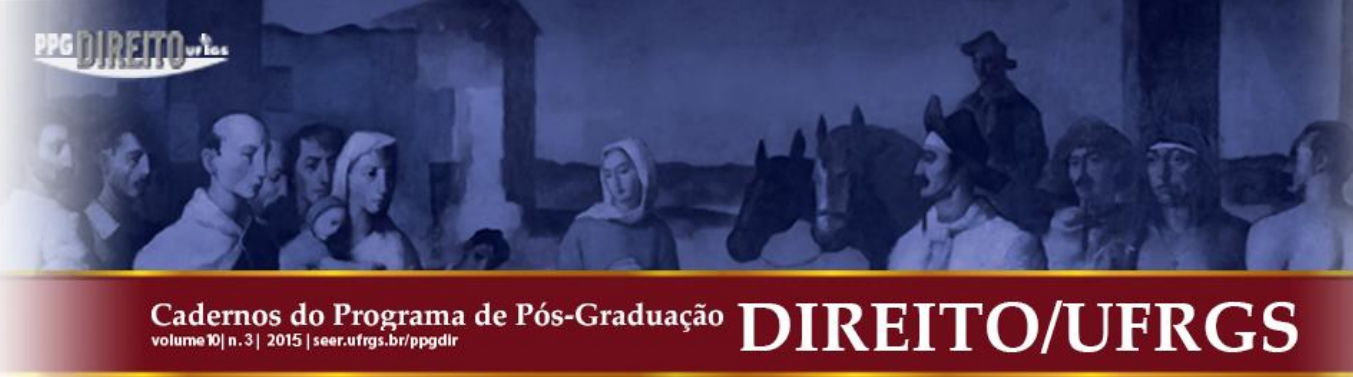

\section{REFERÊNCIAS}

ANTEPROJETO DO NOVO CÓDIGO DE PROCESSO CIVIL. Disponível em: <http://www.senado.gov.br/senado/novocpc/pdf/Anteprojeto.pdf>. Acesso em: 20 nov. 2014.

CALMON, Petrônio. Fundamentos da Mediação e da Conciliação. 2a ed. Brasília: Gazeta Jurídica, 2013.

COBB, Sara; RIFKIN, Janet. Practice and Paradox: Deconstructing Neutrality in Mediation. Law and Society Inquiry, n. 16, p. 35, 1991.

JAYME, Erik. Entrevista concedida para a seção "Diálogo com a Doutrina" da Revista Trimestral de Direito Civil (RTDC) e publicada no ano 1, vol. 3 jul./set. 2000, p. 289-293.

JEVEAUX, Geovany Cardoso. A simbologia da imparcialidade do juiz. Rio de Janeiro: Forense, 1999.

MARQUES, Bruno Pereira; MAZZEI, Rodrigo Reis. Estatuto da Cidade e o Novo Código de Processo Civil: primeiras considerações sobre o impacto e a simbiose dos diplomas. Inédito, 2015.

MARQUES, Cláudia Lima. Superação das antinomias pelo diálogo das fontes: o modelo brasileiro de coexistência entre o Código de Defesa do Consumidor e o Código Civil de 2002. Revista da Esmese, n. 07, 2004.

NOVO CÓDIGO DE PROCESSO CIVIL. Disponível em: <http://www.planalto.gov.br/ccivil_03/_Ato2015-2018/2015/Lei/L13105.htm>. Acesso em: 14 jul. 2015.

TARTUCE, Fernanda. Mediação no Novo CPC: questionamentos reflexivos, p. 14. Disponível em:<http://www.fernandatartuce.com.br/site/aulas/doc_view/339-mediacao-nonovo-cpc-tartuce.html>. Acesso em: 25 nov. 2014.

VAZ, Paulo Afonso Brum. Lei de mediação e conciliação tem pontos positivos e algumas falhas, pp. 6-7. Artigo publicado no site Consultor Jurídico. Disponível em: $<$ http://www.conjur.com.br/2015-jul-03/paul-vaz-lei-mediacao-pontos-positivos-algumasfalhas>. Acesso em: 05 jul. 2015. 


\section{सDDIREM

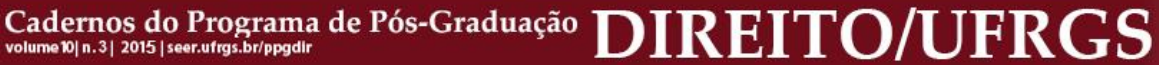

ZAGREBELSKY, Gustavo. El derecho dúctil: ley, derechos, justicia. Traducción de Marina Gascón. Madri: Editora Trotta, 2002.

Submissão: 09/09/2015

Aceito para Publicação: 09/12/2015 
